CIVICS EDUCATION AND SOCIAL SCIENSE JOURNAL(CESSJ)

Volume 2 Nomor 1 Bulan Juni 2020

\title{
SOCIOLOGY SHORT MOVIE: KERJASAMA KONKRET DAN PENDORONG MINAT BELAJAR
}

\author{
Penulis \\ Fatoni Ihsan \\ Guru Sosiologi SMAN 4 Tambun Selatan \\ Mahasiswa Pascasarjana Sosiologi Universitas Indonesia \\ Email: fatoniihsan@gmail.com
}

\begin{abstract}
ABSTRAK
Tulisan ini dilatari oleh program literasi digital abad 21 dan era industri 4.0. Kondisi yang menuntut inovasi pembelajaran digital agar siswa mampu menyesuaikan diri dengan perkembangan zaman. Apabila guru sebagai garda terdepan dalam proses pembelajaran hanya menggunakan pembelajaran konvensional - ceramah, tidak link and match dengan perkembangan zaman, maka kemampuan guru akan terlampaui oleh siswa di era milenium ini. Sociology Short Movies (SOSMOV) hadir sebagai solusi pembelajaran yang inovatif dan inspiratif sekaligus penyesuaikan dengan perkembangan teknologi saat ini yang kian canggih. Penelitian tindakan kelas (PTK) ini menggunakan pendekatan kualitatif.

Secara umum, PTK adalah penelitian tindakan (action research) yang dilaksanakan oleh guru di dalam kelas. Tujuannya untuk meningkatkan dan atau memperbaiki kualitas pembelajaran di sekolah, meningkatkan relevansi, mutu, serta efisiensi pengelolaan pendidikan. Penelitian SOSMOV ini termasuk penelitian tindakan kelompok (collaborative action research) dan menggunakan PTK model Kurt Lewin. Proyek pembuatan film ini melibatkan penguasaan konten, komitmen, dan kerjasama kelompok. Persamaan kepentingan, cukup pengetahuan (stock of knowledge) dan pengendalian terhadap diri sendiri (self control). Implikasinya interaksi sosial diantara anggota kelompok menjadi lebih dalam dan siswa belajar memahami perbedaan karakter satu sama lain. Fungsi laten proses pembuatan SOSMOV yaitu terciptanya solidaritas kelompok yang positif, keterampilan komunikasi, serta meningkatnya minat belajar siswa terhadap sosiologi. Kerjasama dan peningkatan minat belajar itulah yang dibangun dalam proses pembuatan SOSMOV.
\end{abstract}

Kata kunci: SOSMOV, kerjasama, dan sosiodrama

JORNAL PROGDI PPKn, FKIP UNIVET BANTARA SUKOHARJO BEKERJA SAMA DENGAN ASSOSIASI PROFESI PENDIDIKAN PANCASILA DAN KEWARGANEGARAAN (AP3KNI) JAWA TENGAH 
CIVICS EDUCATION AND SOCIAL SCIENSE JOURNAL(CESSJ)

Volume 2 Nomor 1 Bulan Juni 2020

\title{
SOCIOLOGY SHORT MOVIE: \\ COOPERATION AND MOTIVATION FOR LEARNING
}

\author{
Author \\ Fatoni Ihsan \\ Teacher in Senior High School 4 South Tambun \\ Graduate Students in Sociology, University of Indonesia \\ Email: fatoniihsan@gmail.com
}

\begin{abstract}
This paper is motivated by the digital literacy program of the 21 st century and the industry revolution 4.0. That conditions require digital learning innovation so that students are able to adjust to the times. If the teacher as the frontline in the learning process uses only conventional learning - lectures, doesn't link and match with the times, the ability of teachers will be exceeded by students in this millennium era. Sociology Short Movies (SOSMOV) exists as an innovative and inspirational learning solution while adjusting to the increasingly sophisticated technological developments. Penelitian Tindakan Kelas (PTK) or Classroom Action Research uses a qualitative approach. In general, PTK is action research conducted by teachers in the classroom. The aim is to improve and upgrade the quality of learning in schools, and efficiency of education management. The SOSMOV research includes collaborative action research and Kurt Lewin's PTK. This filmmaking project involves mastery of content, commitment, and group collaboration. Equality of interest, enough knowledge (stock of knowledge) and self-control. The implication is that social interaction between group members becomes deeper and students learn to understand the differences in character from one another. The latent function of the SOSMOV making process is the creation of positive group solidarity, communication skills, and increased student interest in sociology. Collaboration and increased interest in learning is what was built in the process of making SOSMOV.
\end{abstract}

\section{Keywords: SOSMOV, Cooperation, Sociodramatic Play}




\section{PENDAHULUAN}

Perkembangan suatu masyarakat berjalan lurus dengan perkembangan tingkat pendidikan. Sebabnya ialah kebudayaan dalam suatu peradaban masyarakat tercipta atas proses pendidikan. Sebagaimana yang diutarakan oleh Miguel Fernandez Ferez bahwa, pendidikan merupakan soal vital bagi tiap segi kemajuan dan perkembangan manusia, dan kedudukannya dalam penentuan kebijakan (policy-making) nasional maupun internasional bertumbuh secara tunak (Ferez, 1982: 11). Ferez menambahkan bukti sejarah saat akhir Perang Dunia Kedua, pendidikan telah menjadi sorotan pandangan dunia dengan penempatan anggaran pendidikan pada urutan kedua di bawah anggaran kemiliteran.

Pendidikan dalam perspektif global, merupakan proses transformasi pengetahuan dan keterampilan. Kedua proses tersebut terjadi dalam relasi sosial para aktor pendidikan yakni guru dan siswa. Guru mempunyai status dan peran yang dipandang penting memiliki pengaruh besar terhadap kualitas proses dan hasil pendidikan. Karena guru berada di posisi terdepan yang berinteraksi langsung dengan siswa sebagai subyek pendidikan. Sementara itu, siswa sebagai subyek didik memiliki pribadi yang otonom, memiliki potensi untuk ditumbuhkembangkan, serta memiliki permasalahan yang dijumpai dalam hidupnya.

Menarik dalam konteks yang lebih kecil yaitu pembelajaran ilmu sosial di ruang kelas, telah beredar adagium bagi siswa sekolah menengah bahwa ilmu sosial adalah ilmu menghapal. Termasuk di dalamnya yaitu ilmu sejarah, ekonomi, geografi, dan khususnya sosiologi. Pandangan demikian jelas keliru yang disebabkan oleh metode pembelajaran ilmu sosial yang konvensional di ruang kelas. "Aku mendengar, maka aku tahu. Aku melihat, maka aku ingat. Aku melakukan, maka aku bisa." Begitulah pernyataan Confusius - seorang filsuf yang memengaruhi dunia pendidikan Timur - memperkenakan pembelajaran yang progresif dari sekadar metode ceramah.

Mengacu program literasi digital abad 21, diperlukan inovasi pembelajaran digital agar siswa mampu menyesuaikan diri dengan perkembangan zaman. Sebagaimana telah diingatkan oleh Wardiman Djojonegoro, "Dunia pendidikan harus link and match dengan perkembangan zaman.” (Djojonegoro, 2018). Apabila 
CIVICS EDUCATION AND SOCIAL SCIENSE JOURNAL(CESSJ)

Volume 2 Nomor 1 Bulan Juni 2020

guru sebagai garda terdepan dalam proses pembelajaran tidak link and match dengan perkembangan zaman, maka kemampuan guru akan terlampaui oleh siswa di era milenium ini.

Penulis sebagai pendidik telah melaksanakan Penelitian Tindakan Kelas (PTK), PTK ini diselenggarakan pada salah satu Sekolah Menengah Atas Negeri Tambun Selatan Kabupaten Bekasi, Provinsi Jawa Barat. Berdasarkan data statistik, Provinsi Jawa Barat sendiri diprediksi memiliki jumlah penduduk 48,6 juta jiwa pada 2018. Sebanyak 33,16 juta jiwa pendudukya merupakan usia produktif (15-64 tahun) dan 15,52 juta jiwa usia tidak produktif (0-14 tahun dan $65+$ tahun). (BPS dan United Population Fund, 2018).

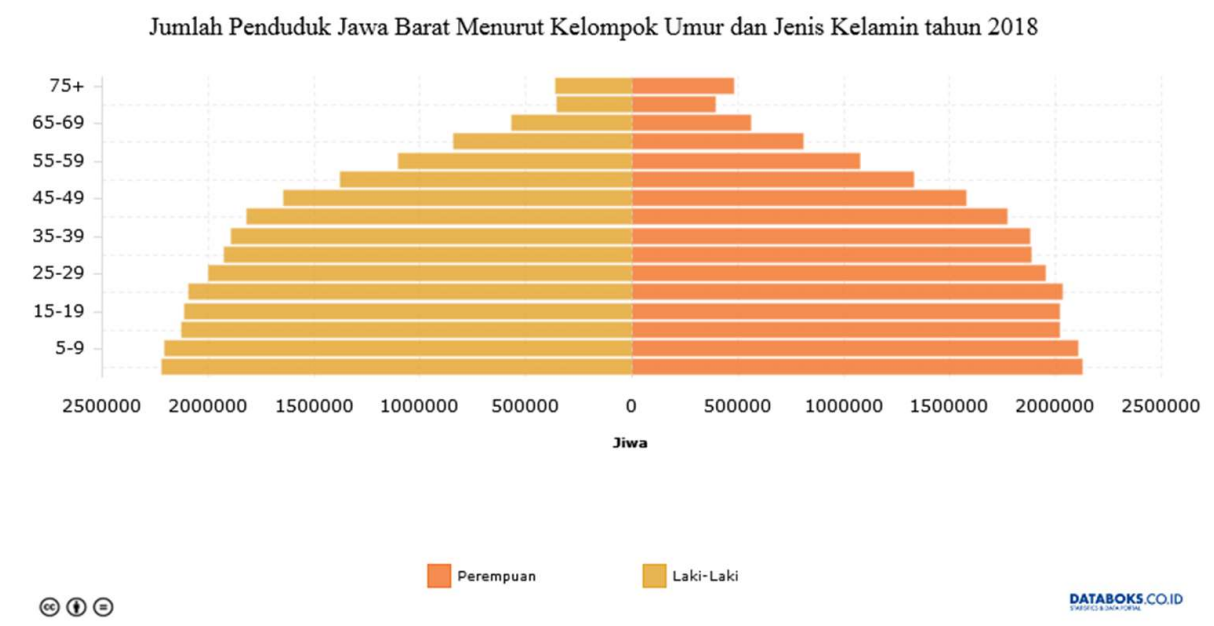

Kondisi ini sangat krusial dengan angka ketergantungan penduduk Jawa Barat terhadap usia produktif sebesar $47 \%$. Dunia pendidikan adalah salah satu lembaga yang harus berperan mengembangkan keterampilan penduduk usia produktifagar dapat bersaing dan berdaya guna.

Berdasarkan konteks sosio-ekonomi demikianlah penulis sebagai guru sosiologi perlu merencanakan, melakukan, dan selanjutnya mengevaluasi, pembelajaran yang inovatif dan inspiratif bagi siswa jurusan ilmu sosial. Sociology Short Movies (SOSMOV) hadir sebagai solusi pembelajaran yang inovatif dan inspiratif sekaligus penyesuaikan dengan perkembangan teknologi saat ini yang kian canggih. Pada prinsipnya SOSMOVadalah aplikasi dari metode Pembelajaran Berbasis Proyek (PBL). Metode PBL ini menggunakan proyek sebagai media, peserta didik melakukan eksplorasi, penilaian, interpetasi, sintesis, dan informasi sebagai hasil belajar. 
CIVICS EDUCATION AND SOCIAL SCIENSE JOURNAL(CESSJ)

Volume 2 Nomor 1 Bulan Juni 2020

PBL SOSMOV bertujuan mengintegrasikan masalah sosial yang ada, pengetahuan tentang konflik dan integrasi sosial (silabus sosiologi kelas XI), serta pengalaman nyata dari aktivitas siswa. Dengan begitu diharapkan siswa mampu memahami konsep konflik dan integrasi sosial dengan melakukan investigasi tentang suatu kasus dan menemukan solusi yang disampaikan melalui film yang menghibur. Selain itu peserta didik dapat melihat, mendengar, meneliti, bahkan memperagakan apa yang dihadapinya, sehingga secara langsung softskill literasi abad 21 - public speaking, management, graphic design - siswa dapat berkembang serta mengambil makna pembelajaran dalam bentuk audio-visual.

Enam bulan berjalan pasca proses pembuatan film hingga kegiatan nonton bareng sebagai refleksi dan apresiasi, penulis melakukan dua evaluasi; nilai akademik dan minat siswa terhadap sosiologi. Hasilnya adalah terjadi peningkatan nilai akademis berdasarkan hasil ujian, dan meningkatknya minat belajar siswa terhadap sosiologi berdasarkan hasil wawancara 5 siswa perwakilan masing-masing kelas IPS yang menjadi informan. Visi dari PBL SOSMOV ini yaitu peningkatan semangat belajar siswa serta terciptanya pembelajaran yang inovatif dan bermakna.

\section{KAJIAN PUSTAKA}

\section{Cooperation}

PBL SOSMOV memerlukan serangkaian proses yang telah diuraikan dalam pendahuluan sebelumnya, namun tidak akan terlaksana dengan maksimal tanpa adanya kerjasama. Kerjasama antara siswa dengan guru, siswa dengan anggota kelompoknya, serta siswa dengan stakeholder setempat.

Kerjasama dalam istilah sosiologi dimaknai sebagai suatu usaha bersama antar individu atau kelompok manusia untuk mencapai tujuan bersama. Suatu proses kerjasama akan berlangsung ideal dengan tiga syarat; Pertama, subyek yang terlibat dapat digerakan untuk mencapai suatu tujuan bersama. Kedua, adanya kesadaran bahwa tujuan tersebut di kemudian hari mempunyai manfaat bagi semua. Ketiga, terciptanya iklim yang menyenangkan dalam pembagian kerja serta balas jasa yang akan diterima.

Seorang tokoh sosiologi modern Charles H.Cooley (Cooley dalam Soekanto, 2013: 66),memiliki konsep yang tepat dalam memandang kerjasama proyek pembuatan SOSMOV ini:

JORNAL PROGDI PPKn, FKIP UNIVET BANTARA SUKOHARJO BEKERJA SAMA DENGAN ASSOSIASI PROFESI PENDIDIKAN PANCASILA DAN KEWARGANEGARAAN (AP3KNI) JAWA TENGAH 
CIVICS EDUCATION AND SOCIAL SCIENSE JOURNAL(CESSJ)

Volume 2 Nomor 1 Bulan Juni 2020

"kerjasama timbul apabila orang menyadari bahwa mereka mempunyai kepentingan-kepentingan yang sama dan pada saat yang bersamaan mempunyai cukup pengetahuan dan pengendalian terhadap diri sendiri untuk memenuhi kepentingankepentingan tersebut; kesadaran akan adanya kepentingankepentingan yang sama dan adanya organisasi merupakan faktafakta penting dalam kerjasama yang berguna"

\section{Sosiodrama}

Secara sederhana, Sociology Short Movies adalah transformasi metode pembelajaran yang lebih progresif. Segala proses dan unsur yang ada dalam metode sosiodrama tetap ada. Prinsip dan tujuan Sosiodrama dengan SOSMOV ini sama. Hanya ditambah proses pengambilan gambar, latar yang berbeda-beda, kemudian dipresentasikan dalam bentuk digital audio-visual.Penerapan metode sosiodrama dinilai cocok dengan pembalajaran sosiologi. Sebabnya ialah pada saat simulasi/drama siswa akan merasa seolah-olah menjadi aktor yang melakukan tindakan sosial yang dekat dengan realitas kehidupan sosial mereka, sehingga esensi dari konteks sosial akan mudah diserap oleh siswa. Esensi itulah yang diharapkan menghasilkan perubahan tingkah laku ideal pada siswa.

Tujuan utama metode sosiodrama yaitu mengarahkan pada pemecahan masalah-masalah yang menyangkut hubungan antarmanusia, terutama yang menyangkut kehidupan peserta didik. Prinsipnya, bermain peran atau sosiodrama adalah metode mengajar yang dalam pelaksanaannya peserta didik mendapat tugas dari guru untuk mendramatisasikan suatu situasi sosial yang mengandung suatu problem, agar peserta didik dapat memecahkan suatu masalah yang muncul dari suatu situasi sosial (Sagala, 2010: 213).

Menurut Rosyidi proses sosiodrama memberikan contoh langsung dari perilaku manusia yang berfungsi sebagai media bagi siswa untuk: (1) mengeksplorasi perasaan siswa, (2) memperoleh wawasan sikap, nilai, dan persepsi, (3) mengembangkan siswa dalam pemecahan masalah, keterampilan, dan sikap, (4) serta mengeksplorasi materi pelajaran dengan cara yang bervariasi (Rosyidi: 4). Inti dari sosiodrama yaitu keterlibatan peserta dan pengamat dalam situasi masalah nyata, yang kemudian merangsang keinginan untuk resolusi dan pemahaman yang melahirkan involvement. 
CIVICS EDUCATION AND SOCIAL SCIENSE JOURNAL(CESSJ)

Volume 2 Nomor 1 Bulan Juni 2020

\section{METODE}

Penelitian pada artikel ini diselenggarakan dua periode. Pertama, Januari hingga April 2018. Kedua, bulan September 2018. Kelas yang terlibat adalah seluruh XII IPS di SMAN 4 Tambun Selatan. Satu kelas terdiri dari 4 kelompok dan masing-masingnya satu proyek film. Penelitian ini menggunakan pendekatan penelitian kualitatif, yakni pendekatan penelitian yang dimulai dengan penggunaan teoritis yang membentuk atau memengaruhi studi tentang permasalahan riset terkait dengan makna yang dikenakan. PBL SOSMOV inilah yang menjadi basis kegiatan penelitian tindakan kelas. Secara umum, penelitian tindakan kelas adalah penelitian tindakan (action research) yang dilaksanakan oleh guru di dalam kelas (Kusumah, 2012: 9). Tujuannya untuk meningkatkan dan atau memperbaiki kualitas pembelajaran di sekolah, meningkatkan relevansi, mutu, serta efisiensi pengelolaan pendidikan. Penelitian SOSMOV ini termasuk penelitian tindakan kelompok (collaborative action research) dan menggunakan PTK model Kurt Lewin.

\section{Skema 1.}

\section{Siklus PTK menurut Kurt Lewin}

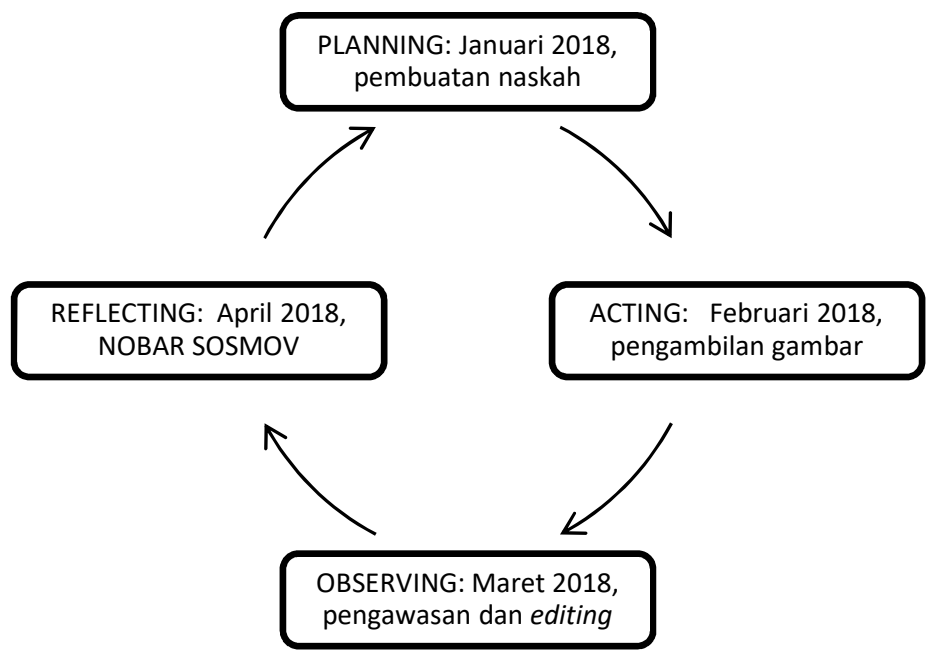

Sumber: Diolah dari Siklus PTK Kurt Lewin 
CIVICS EDUCATION AND SOCIAL SCIENSE JOURNAL(CESSJ)

Volume 2 Nomor 1 Bulan Juni 2020

\section{HASIL PENELITIAN DAN PEMBAHASAN}

\section{SOSMOV Sarana Belajar Bekerjasama}

Sociology Short Movies (SOSMOV) adalah salah satu bentuk pembelajaran berbasis proyek (project based learning/ PBL). PBL sendiri timbul dari gagasan Filsuf yang bernama John Dewey tentang konsep "learning by doing”, yaitu proses perolehan hasil belajar dengan mengerjakan tindakan-tindakan sesuai tujuan tertentu. Proyek pembuatan film ini membutuhkan managemen yang komprehensif berupa penguasaan konten, komitmen, dan yang terpenting yakni kerjasama kelompok.

SOSMOV adalah tugas akhir sekaligus syarat ketuntasan belajar mapel sosiologi kelas XI semester genap. Durasi waktu pengerjaan selama tiga bulan dengan kesepakatan bersama antara guru dengan siswa. Tuntutan tugas itu menjadi salah satu faktor terjalinnya kerjasama diantara anggota kelompok siswa. Hal ini senada dengan pernyataan Cooley:kerjasama timbul apabila orang menyadari bahwa mereka mempunyai kepentingan-kepentingan yang sama. Seperti awalnya yang dirasakan oleh Alifianita, "sebenernya pas bapak ngasih tugas itu, aduh sebenernya saya juga males pak bikin film, waktunya lama kan ya pak. Tapi mau gimana lagi namanya tugas kan harus dikerjakan. Akhirnya saya mengerjakannya dengan senang hati" (Alifianita, 2018). Persamaan kepentingan akan pemenuhan tugas akhir itulah yang mendorong mereka bekerjasama. Alifianita melanjutkan,“Alhamdulillah kelompok-kelompok saya, mau jalan, maksudnya lancar buat filmnya, walaupun ada si Encos tapi kita berusaha menyesuaikan, jadi semua lancar pak, alhamdulillah."

Kemudian ada dua unsur yang harus ada untuk memenuhi kepentingan bekerjasama bagi Cooley,yaitu cukup pengetahuan (stock of knowledge) danpengendalian terhadap diri sendiri (self control). Kedua unsur ini dialami langsung oleh siswa dalam pembuatan film, "kebersamaan yang pasti, terus pembagian waktunya, terus keseriusan, terus harus kompak juga. Ga boleh egois, kaya marah-marah mulu gitu, itu kan pasti ada. Cuma harus kaya yang tahan-tahan diri aja, sama-samacapek jadi harus ngerti” (Farah, 2018).

Setelah proyek pembuatan film pendek sosiologi diselesaikan oleh siswa, mereka mendapat pelajaran baru yang diperoleh dari pengalaman langsung, pengalaman bekerjasama. "Jadi pas saya dikasih tugas itu kan saya jadi tau sisi lain dari Encos itu gimana, sisi lain dari Hasta, Moza, kaya gimana, itu ada hikmahnya 
CIVICS EDUCATION AND SOCIAL SCIENSE JOURNAL(CESSJ)

Volume 2 Nomor 1 Bulan Juni 2020

si pak." Interaksi sosial diantara anggota kelompok lebih dalam dan belajar memahami perbedaan karakter satu sama lain.

Selain itu, siswa dapat menyadari urgensi solidaritas kelompok yang positif serta mengasah keterampilan komunikasi. Seorang siswa yang bernama Fazri mengungkapkan, "hikmah yang bisa saya ambil, satu itu kekompakan, berkomunikasi itu penting, trus yang kedua itu gimana cara kita nyikapin yang bener-bener ga bisa, males, harus bener-bener sabar itu otomatis" (Fazri, 2018). Solidaritas kelompok, komunikasi, dan penyesuaian diri terhadap situasi merupakan fakta-fakta penting yang berguna dalam proses kerjasama.

\section{Sosiodrama dan Fungsi Latennya}

Bermain peran dalam pembelajaran atau yang lebih dikenal dengan sosiodrama, dipelopori oleh George Shaftel melalui bukunya yang berjudul RolePlaying in Social Values: Decision-making in the Social Studies. Sebuah metode yang menjadi miniatur kehidupan sosial di masyarakat. Penggunaan sosiodrama dinilai tepat untuk diterapkan dalam fase merefleksikan materi sosiologi. Alasannya, dibuat berdasarkan asumsi bahwa sangatlah mungkin menciptakan analogi otentik ke dalam suatu situasi permasalahan kehidupan nyata.

Apabila guru sosiologi mempertahankan dan hanya menggunakan metode konvensional - ceramah, akan mendorong guru terjebak dalam discruption era yang menandai Era Industri 4.0 saat ini. Pembelajaran yang tekstual di era industri 4.0 sudah off out date, dibutuhkan kondisi belajar yang empiris dan kontekstual. Jika tidak ada inovasi menjawab tantangan zaman, maka discruption era akan berdampak pada dunia pendidikan yaitu kemampuan guru akan terlampaui oleh siswa yang menguasai teknologi informasi. Salah satu metode yang mengarahkan pada pemecahan masalah hubungan antarmanusia adalah sosiodrama. Menurut Uno, sosiodrama dapat mendorong siswa mengekspresikan perasaannya dan bahkan melepaskannya serta proses psikologis melibatkan sikap, nilai, dan keyakinan kita serta kesadaran melalui keterlibatan spontan yang disertai analisis (Uno, 2009: 25).

Saat pembuatan film berlangsung, beradu peran dengan anggota kelompoknya, siswa dapat menghubungkan antara teori-teori sosiologi dengan konteks kehidupan sosial yang mereka skenariokan. Monita mengungkapkan apa yang dirasakan saat bermain peran, "waaa bikin film ni, jadinya lebih seneng, karena lebih cenderung ke praktek, terus kebetulan objek kajian sosiologi tuh tepat untuk dijadikan praktek atau penelitian, jadinya antusias banget mengikuti pelajaran sosiologi” (Monita, 
CIVICS EDUCATION AND SOCIAL SCIENSE JOURNAL(CESSJ)

Volume 2 Nomor 1 Bulan Juni 2020

2018). Otoritas yang diberikan kepada siswa untuk membuat skenario filmnya sendiri, tetap dalam tema konflik dan integrasi, memberi peluang untuk berimajinasi serta keleuasaan menyampaikan pesan. "Banyak banget pikiran yang ingin kita sampaiin akhirnya nah tersampaikan di film sosiologi itu." tutur Monita kembali.

Ketika memainkan peran membutuhkan beberapa skill khusus agar tercipta momen yang ideal. Keterampilan berkomunikasi melalui berbicara dan gestur tubuh, mengolah sikap saat berinteraksi, serta mengingat pesan yang harus disampaikan. Tahap selanjutnya yaitu penggabungan dan editing video menjadi satu kesatuan film pendek sosiologi. Syarat berjalannya editing video yaitu kemampuan dasar siswa mengoperasikan komputer dan penguasaan atas software multimedia. Tuntutan yang ada akhirnya mendorong siswa untuk mempelajari keterampilan lain di luar mata pelajaran sekolah, yaitu keterampilan tepat guna. Sebabnya ialah era industri 4.0 manusia dihadapkan dengan digitalisasi dan kecepatan informasi. Maka keahlian atas teknologi informasi dan multimedia menjadi keharusan bila tidak ingin tertinggal oleh zaman.

Setelah proyek film berjalan siswa menunjukan timbal-balik yang positif. Berdasarkan pengakuan dari Burhanuddin, "nah kita lebih belajar di luar ruangan, refreshing. Sedangkan kalau di kelas kan ga terlalu memadai sumber dan media pembelajarannya" (Aziz, 2018). Begitupun dengan pengakuan Adella Farah yang semakin tertarik mempelajari sosiologi, "jadi makin ga sabar nunggu tantangan itu. Soalnya seru aja gitu pak, pengetahuan baru.'Pengakuan atas peningkatan minat terhadap pelajaran sosiologi tidak hanya diungkapkan melalui lisan. Secara tidak langsung peningkatan minat karena metode pembelajaran inovatif yang diwujudkan dengan SOSMOV bisa dilihat dari perbandingan hasil murni PTS dengan PAS Genap 2017/2018:

Tabel 1.

Nilai Rata-rata Ujian PTS dan PAS Genap 2017/2018

\begin{tabular}{|l|c|c|c|c|}
\hline \multicolumn{1}{|c|}{ KELAS } & XI IPS 1 & XI IPS 2 & XI IPS 3 & XI IPS 4 \\
\hline $\begin{array}{l}\text { NILAI RATA-RATA } \\
\text { PTS GENAP 17/18 }\end{array}$ & 61,2 & 70,7 & 73,7 & 68,6 \\
\hline $\begin{array}{l}\text { NILAI RATA-RATA } \\
\text { PAS GENAP 17/18 }\end{array}$ & 65 & 81 & 84 & 76 \\
\hline
\end{tabular}

Sumber: Diolah dari penilaian kognitif tahun pelajaran 2017/2018

JORNAL PROGDI PPKn, FKIP UNIVET BANTARA SUKOHARJO BEKERJA SAMA DENGAN ASSOSIASI PROFESI PENDIDIKAN PANCASILA DAN KEWARGANEGARAAN (AP3KNI) JAWA TENGAH 
CIVICS EDUCATION AND SOCIAL SCIENSE JOURNAL(CESSJ)

Volume 2 Nomor 1 Bulan Juni 2020

\section{SIMPULAN}

Pendidikan merupakan proses transformasi pengetahuan dan keterampilan. Kedua proses tersebut terjadi dalam relasi sosial para aktor pendidikan yakni guru dan siswa. Dalam konteks kekinian yaitu program literasi digital abad 21, diperlukan inovasi pembelajaran digital agar siswa mampu menyesuaikan diri dengan perkembangan zaman. Apabila guru sebagai garda terdepan dalam proses pembelajaran tidak link and match dengan perkembangan zaman, maka kemampuan guru akan terlampaui oleh siswa di era milenium ini. Demikianlah sebagai guru sosiologi perlu merencanakan, melakukan, dan selanjutnya mengevaluasi, pembelajaran yang inovatif dan inspiratif bagi siswa khususnya jurusan ilmu sosial. Sociology Short Movies (SOSMOV) hadir sebagai solusi pembelajaran yang inovatif dan inspiratif sekaligus penyesuaikan dengan perkembangan teknologi saat ini yang kian canggih.

Proyek pembuatan film ini membutuhkan managemen yang komprehensif berupa penguasaan konten, komitmen, dan yang terpenting yakni kerjasama kelompok. Persamaan kepentingan akan pemenuhan tugas akhir itulah yang mendorong siswa bekerjasama. Selain itu, ada dua unsur yang ada untuk memenuhi kepentingan bekerjasama yaitu cukup pengetahuan (stock of knowledge) dan pengendalian terhadap diri sendiri (self control). Implikasinya interaksi sosial diantara anggota kelompok menjadi lebih dalam dan siswabelajar memahami perbedaan karakter satu sama lain. Serta akhirnya siswa dapat menyadari urgensi solidaritas kelompok yang positif dan meningkatkan keterampilan komunikasi.Setelah proses pembuatan pembuatan film hingga kegiatan nonton bareng sebagai refleksi dan apresiasi. Hasilnya adalah terjadi peningkatan minat belajar siswa dan peningkatan nilai akademis berdasarkan hasil ujian.

\section{REFERENSI}

Badan Pusat Statistik. (2018, Agustus 2). 2018, Angka Ketergantungan Penduduk Jawa Barat Sebesar 47\%. Diambil kembali dari Kata Data: https://databoks.katadata.co.id/datapublish/2018/08/02/2018-angkaketergantungan-penduduk-jawa-barat-sebesar-47

Creswell, J. W. (2007). Qualitative Inquiry \& Research Design: Choosing Among Five Approaches (2nd ed.). London: Sage Publications.

Ferez, M. F., \& Gopinathan, S. (1982). Krisis dalam Pendidikan. Jakarta: Balai Pustaka.

IKA UNJ. (2018, November 20). Seminar Pendidikan Nasional 2018. (M. R. Luddin, W. Djojonegoro, \& R. Robert, Pemain) Pascasarjana Universitas Negeri Jakarta, Jakarta. 
CIVICS EDUCATION AND SOCIAL SCIENSE JOURNAL(CESSJ)

Volume 2 Nomor 1 Bulan Juni 2020

Kusumah, W., \& Dwitagama, D. (2012). Mengenal Penelitian Tindakan Kelas. Jakarta: Indeks.

Rosyidi, B. (t.thn.). Model Pembelajaran Role Playing: Studying Social Behaavior and Values. Diambil kembali dari academia: https://www.academia.edu/13181699/MODEL_PEMBELAJARAN_ROL E_PLAYING_STUDYING_SOCIAL_BEHAVIOR_AND_VALUES

Sagala, S. (2010). Konsep dan Makna Pembelajaran: Untuk Membantu Memecahkan Problematika Belajar dan Mengajar. Bandung: Alfabeta.

Soekanto, S. (2013). Sosiologi Suatu Pengantar. Jakarta: Rajawali Press.

Uno, H. B. (2009). Teori Motivasi dan Pengukurannya. Jakarta: Bumi Aksara. 
CIVICS EDUCATION AND SOCIAL SCIENSE JOURNAL(CESSJ)

Volume 2 Nomor 1 Bulan Juni 2020

\section{LAMPIRAN}

\section{Dokumentasi SOSMOV}
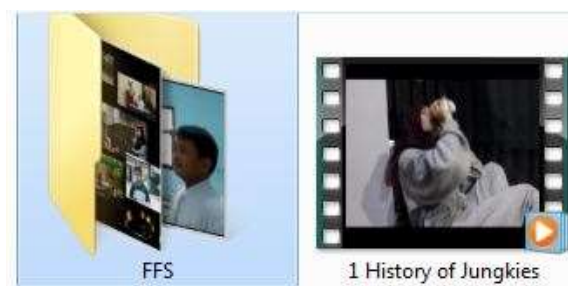

1 History of Jungkies
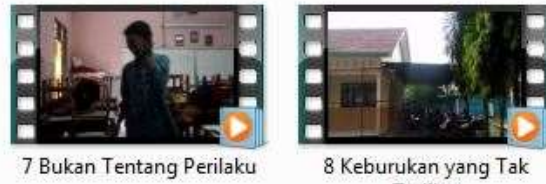

8 Keburukan yang Tak Terlihat

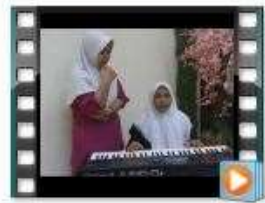

film 11 ips 2

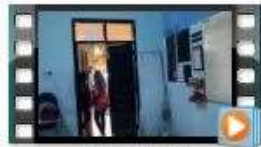

OPPOSTE1

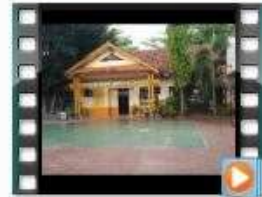

film kel panca dkk

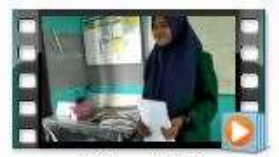

Pilihan Kuliah

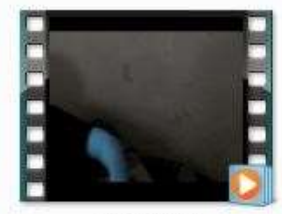

2 Rapunzel
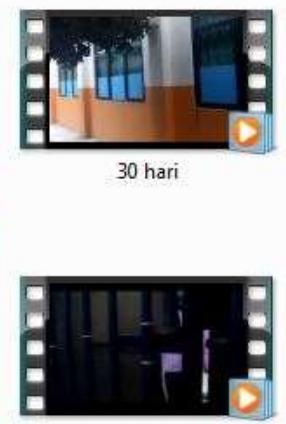

hadiah terindah dari ummi

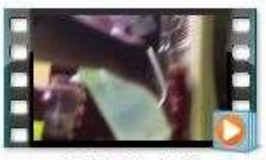

XI IPS 2 (windi)
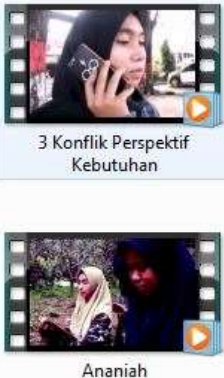

Ananiah

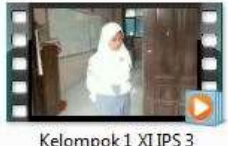

Kelompok 1 XI IPS 3

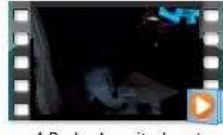

4 Perbedaan itu berat

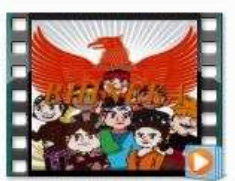

bhineka

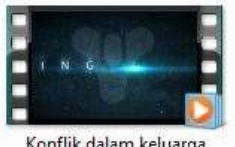

Konflik dalam keluarga

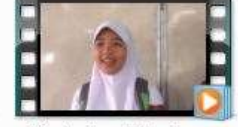

5 Perbedaan Kebudayaan
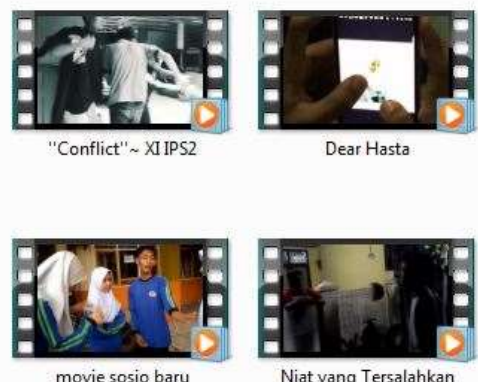

JORNAL PROGDI PPKn, FKIP UNIVET BANTARA SUKOHARJO BEKERJA SAMA DENGAN 